Published in final edited form as:

Drug Metab Dispos. 2006 May ; 34(5): 756-764.

\title{
Rifampicin Induction of CYP3A4 Requires PXR crosstalk with HNF4 $\alpha$ and co-activators, and suppression of SHP gene Expression
}

\author{
Tiangang Li and John Y.L. Chiang \\ Department of Biochemistry and Molecular Pathology, Northeastern Ohio Universities College of \\ Medicine, Rootstown, Ohio 44272,USA
}

\begin{abstract}
Bile acids and drugs activate PXR to induce CYP3A4, which is the predominant cytochrome P450 enzymes expressed in the liver and intestine and plays a critical role in detoxifying bile acids and drugs, and protecting against cholestasis. The aim of this study is to investigate the molecular mechanism of PXR cross talk with other nuclear receptors and co-activators in regulating human CYP3A4 gene transcription. Rifampicin dose-dependently induced the CYP3A4 but inhibited small
\end{abstract}

Correspondence address: John Y. L. Chiang, Ph.D., Department of Biochemistry and Molecular Pathology, Northeastern Ohio Univ's College of Medicine, 4209 State Route 44, P. O. Box 95, Rootstown, OH 44272, Tel: 330-325-6694, Fax: 330-325-5910, E-mail: jchiang@neoucom.edu.

This work was supported by NIH grants DK44442 and DK31584.

Abbreviations:

ChIP chromatin immunoprecipitation assay

CYP3A4

cytochrome P4503A4

CYP7A1 cholesterol $7 \alpha$-hydroxylase

FXR

farnesoid X receptor

GST

glutathione S-transferase

HNF4a

hepatocyte nuclear factor $4 \alpha$

LCA

lithocholic acid

PXR

pregnane $\mathrm{X}$ receptor

PGC-1a

peroxisome proliferators-activated receptor $\gamma$ co-activator $1 \alpha$

SHP

small heterodimer partner

SRC-1

steroid receptor coactivator-1

XREM

xenobiotic responsive element module 
heterodimer partner (SHP) mRNA expression levels in primary human hepatocytes. Rifampicin strongly stimulated PXR and HNF4 $\alpha$ interaction, and CYP3A4 reporter activity, which was further stimulated by PGC- $1 \alpha$ and SRC- 1 but inhibited by SHP. Mutation of the putative HNF4 $\alpha$ binding site in the distal xenobiotic responsive element module (dXREM) did not affect CYP3A4 basal promoter activity and synergistic stimulation by PXR and HNF4 $\alpha$. Chromatin immunoprecipitation assays revealed that rifampicin-activated PXR recruited HNF4 $\alpha$ and SRC-1 to the CYP3A4 chromatin. On the other hand, SHP reduced PXR recruitment of HNF4 $\alpha$ and SRC-1 to the CYP3A4 chromatin. The human SHP promoter was stimulated by HNF4 $\alpha$ and PGC- $1 \alpha$. Upon activation by rifampicin, PXR inhibited SHP promoter activity. Results suggest that PXR strongly induces CYP3A4 gene transcription by interacting with HNF4 $\alpha$, SRC-1 and PGC-1 $\alpha$. PXR concomitantly inhibits SHP gene transcription and maximizes the PXR induction of the CYP3A4 gene in human livers. Drugs targeted to PXR may be developed for treating cholestatic liver diseases induced by bile acids and drugs.

\section{INTRODUCTION}

CYP3A4 is the most abundant cytochrome P450 enzymes expressed in the liver and small intestine and plays a crucial role in metabolism and detoxification of xenobiotics and endobiotics (Guengerich, 1999). CYP3A4 has very broad substrate specificity and metabolizes over $50 \%$ of clinical drugs. The expression levels of CYP3A4 vary widely among individuals (Lehmann et al., 1998). Compounds that activate human PXR (NR1I2) also induce CYP3A4 and drug metabolism activity (Bertilsson et al., 1998; Kliewer et al., 1998; Lehmann et al., 1998; Goodwin et al., 2002). An antibiotic rifampicin is a highly efficacious human PXR agonist (Kliewer et al., 2002), and has been used to treat pruritus of primary biliary cirrhosis patients for many years without knowing its molecular mechanism of drug action (Bachs et al., 1989; Hofmann, 2002). The ligand-activated PXR forms a heterodimer with RXR and binds to the AGGTCA-like direct repeats spaced by 3, 4 or 5 bases (DR3, DR4, and DR5), and the everted repeats separated by 6 or 8 bases (ER6 and ER8) located in the PXR target genes (Kliewer et al., 1998). In the human CYP3A4 promoter, PXR binds to an ER6 located in the proximal promoter and a DR3 and ER6 in the distal xenobiotic responsive enhancer module (XREM) located about $8 \mathrm{~kb}$ upstream of the transcription start site (Bertilsson et al., 1998; Lehmann et al., 1998; Goodwin et al., 1999). The maximal induction of the CYP3A4 gene by PXR requires both the proximal ER6 and the distal XREM (Goodwin et al., 1999).

Lithocholic acid (LCA) is the most efficacious bile acid that activates PXR and induces CYP3A4 to catalyze 6-hydroxylation of LCA to hyodeoxycholic acid (Staudinger et al., 2001; Xie et al., 2001). Feeding LCA causes liver damage in Pxr null mice, but transgenic mice expressing a human PXR are protected from bile acid toxicity and cholestasis (Staudinger et al., 2001). PXR inhibits cholesterol $7 \alpha$-hydroxylase (CYP7A1), the regulatory gene in bile acid synthesis, but induces organic anion transport protein 2 , a sinusoidal $\mathrm{Na}^{+}$-independent bile acid transporter (Staudinger et al., 2001). Nuclear receptors interact with their co-activators such as steroid receptor co-activator-1 (SRC-1) or co-repressors and activate or inhibit their target genes. We reported previously that rifampicin-activated PXR interacts with hepatocyte nuclear factor $4 \alpha(\mathrm{HNF} 4 \alpha)$ and blocks HNF4 $\alpha$ recruitment of peroxisome proliferators-activated receptor $\gamma$ co-activator-1 $\alpha$ (PGC-1 $\alpha$ ), and results in inhibition of the human CYP7A1 gene (Li and Chiang, 2004). HNF4 $\alpha$ plays a vital role in liver development and regulation of bile acid synthesis, lipid homeostasis, and xenobiotic response (Stroup and Chiang, 2000; Hayhurst et al., 2001; Kamiya et al., 2003). Both PXR and HNF4 $\alpha$ interact with PGC- $1 \alpha$, which is a nuclear receptor co-activator induced by glucagon and glucocorticoid to regulate gluconeogenesis and bile acid synthesis (De Fabiani et al., 2003; Puigserver et al., 2003; Shin et al., 2003).

HNF4 $\alpha$ induces PXR gene transcription in fetal liver and enhances PXR induction of CYP3A4 (Kamiya et al., 2003; Tirona et al., 2003). It has been reported recently that SHP interacts with 
rifampicin-activated PXR and inhibits the CYP3A4 gene expression in vitro (Ourlin et al., 2003). SHP is a negative nuclear receptor that is induced by bile acid-activated farnesoid $X$ receptor (FXR) and inhibits the CYP7A1 gene (Goodwin et al., 2000; Lu et al., 2000). Therefore, the bile acid-induced FXR/SHP pathway could counteract the bile acid activation of the CYP3A4 gene transcription by PXR. The physiological role of SHP in regulation of CYP3A4 needs to be further studied.

In this study, we investigated the roles of human PXR, HNF4 $\alpha$ and SHP on the regulation of human CYP3A4 gene transcription. Our results suggest that CYP3A4 is subjected to a complex regulation by nuclear receptors and co-activators, and that maximal induction of CYP3A4 gene expression requires concomitant inhibition of SHP gene transcription by PXR.

\section{MATERIALS AND METHODS}

Cell culture. Human hepatoblastoma HepG2 cells were obtained from the American Type Culture Collection (Manassas, VA). Primary human hepatocytes were isolated from human donors (HH1 115, 22 yr male; HH1117, 68 yr female; HH1119, 29 yr female) and were obtained through the Liver Tissue Procurement and Distribution System (LTPADS) of NIH (S. Strom, University of Pittsburgh, Pittsburgh, PA). Cells were cultured and maintained as described previously (Li and Chiang, 2004)

Plasmids. Human CYP3A4/luciferase construct (p3A4-5'dDR3/dER6/pER6-LUC) was obtained from Marie-Jose Vilarem (Institut Federatif de Recherche 24, France). This reporter contains an HNF4 $\alpha$ binding site (DR1) and PXR binding sites (DR3 and ER6) in the distal XREM (dXREM, -7800/-7600), which was linked to a 5'flanking fragment containing a proximal ER6 (pER6) of the human CYP3A4 gene (Drocourt et al., 2002). A human CYP7A1/ Luc reporter (ph-298/Luc) was constructed as described previously (Li and Chiang, 2004). Human SHP/luciferase reporter construct (SHP-luc) containing $2 \mathrm{~kb}$ promoter sequence and expression plasmid (pCDM8-mSHP) were provided by Yoonkwang Lee (Bayor College of Medicine, Houston, TX). Expression plasmids for SHP (pcDNA3-HA-SHP), SRC-1 (pCR3.1hSRC-1A), PGC-1 $\alpha$ (pcDNA3/HA-PGC-1 $\alpha$ ), human RXR (pcDNA3-hRXR), rat HNF4 $\alpha$ (pCMX-rHNF4 $\alpha$ ), and human PXR (pSG5-hPXR) were obtained from H.S. Choi (Chungnam National University, Korea), M. J. Tsai (Bayor College of Medicine, Houston, TX), A. Kralli (The Scripp Research Institute, La Jolla, CA), R. Evans (Scripps Research Institute, La Jolla, CA), W. Chin (Eli Lily Research Laboratories, Indianapolis, ID), and S. Kliewer (University of Texas Southwestern Medical Center, Dallas, TX), respectively. For mammalian hybrid assays, the reporter $5 \mathrm{XUAS}-\mathrm{TK}-\mathrm{Luc}$ contains 5 copies of the upstream activating sequence (UAS) fused upstream of a thymidine kinase minimum promoter (TK) and the luciferase reporter gene. The GAL4 and VP16 fusion plasmids contained the ligand-binding domain (LBD) of nuclear receptors or nuclear receptor-interacting domain (RID) of co-activators fused to Gal4-DBD (DNA binding domain) or VP16-AD (activation domain) vector. Mammalian two-hybrid fusion plasmids used were: pCMX-VP16-rHNF4 (a.a 125 to 364) from D. Moore (Baylor College of Medicine, Houston, TX); Gal4-hPXR-LBD (a.a. 107-434, VP16-SRC-1RID (a.a. 595-780) and VP16-hPXR-LBD (a.a. 107-437) from A. Takeshita (Toranomon Hospital, Tokyo, Japan), and Gal4-PGC-1 $\alpha$ (full length) from A. Kralli (The Scripp Research Institute, La Jolla, CA). Gal4-HNF4 $\alpha$ fusion plasmids pBx-HNF4 $\alpha$-FL (full-length) was obtained from I. Talianidis (Institute of Molecular Biology and Biotechnology Foundation for Research and Technology, Hellas, Herakleion Crete, Greece). For GST fusion protein expressions, pGEX-4T-1 plasmid encoding the Glutathione $S$-transferase (GST) protein was obtained from Amersham Pharmacia Biotech. The pET23a-GST-HNF4 $\alpha$ plasmid encoding a fusion protein of GST with full length human HNF4 was a kind gift from Todd Leff (Wayne State University, Detroit, MI). GST-hPXR-LBD was cloned by inserting PCR-amplified human PXR ligand binding domain (a.a. 241-434) into pGEX-4T-1 BamH1/XhoI sites. GST- 
mSHP containing full length SHP was obtained from D. Moore (Bayor College of Medicine, Houston, TX).

Quantitative real-time PCR assay. Primary human hepatocytes were maintained in 6-well plates. Cells were treated with increasing amount of rifampicin (1-10 $\mu \mathrm{M})$ (Sigma, St. Louis, MO) for $24 \mathrm{~h}$. Total RNA was isolated from the cells using Tri-Reagent (Sigma) according to the manufacturer's protocol. Reverse transcription reactions were performed using RETROscript kit according to manufacturer's instructions (Ambion Inc., Austin, TX). For realtime PCR, samples were prepared according to the PCR Taqman Universal Master Mix 2X protocol (Applied Biosystems, Foster City, CA). Amplification of human ubiquitin C (UBC) was used as an internal reference gene. Quantitative PCR analysis was conducted on the ABI 7500 System software. Relative mRNA expression was quantified using the comparative $C_{T}$ $(\mathrm{Ct})$ method according to the ABI manual. Assay-on-Demand PCR primers and Taqman MGB probe mix used were: human CYP3A4 (Cat. \#: Hs00604506_m1); human CYP7A1 (Cat. \# Hs00167982_ml); human SHP (Cat. \# Hs00222627_ml); human UBC (Cat. \# Hs00824723_m1).

Transient transfection assay. HepG2 cells were grown to $\sim 80 \%$ confluence in 24 -well tissue culture plates. Reporter plasmid $(0.2 \mu \mathrm{g})$ was transfected with expression plasmid $(0.1 \mu \mathrm{g})$ using lipofectamine 2000 reagent (Invitrogen, Carlsbad, CA) according to manufacturer's protocol. The pCMV-galactosidase plasmid $(0.05 \mu \mathrm{g})$ was transfected as an internal standard for normalizing the transfection efficiency in each assay. In some samples empty expression vectors were added to equalize the total amounts of plasmid DNA transfected in each assay. Cells were treated with vehicle (DMSO) or $10 \mu \mathrm{M}$ rifampicin in serum free media for $40 \mathrm{~h}$, and assayed for luciferase reporter activity using Luciferase Assay System (Promega). Luciferase activity was normalized by dividing the relative light units (RLU) by $\beta$ galactosidase activity. Each assay was done in triplicate and individual experiments were repeated at least three times.

Site-directed mutagenesis. Mutations (shown in Fig. 3B) were introduced into the HNF4 $\alpha$ binding site in dXREM of CYP3A4/luciferase construct (p3A4-5'dDR3/dER6/pER6-LUC) using PCR-based QuikChange Site-directed Mutagenesis Kit (Stratagene, La Jolla, CA). Two complementary oligonucleotides containing the mutations were used as PCR primers. PCR reactions were set up according to the manufacturer's instruction using $50 \mathrm{ng}$ of template DNA and $125 \mathrm{ng}$ of primers. PCR cycling parameters were set as following: denaturing at $95^{\circ}$ for $2 \mathrm{~min}$, followed by 18 cycles at $95^{\circ}$ for $30 \mathrm{~s}, 52^{\circ}$ for $1 \mathrm{~min}$, and $68^{\circ}$ for $18 \mathrm{~min}$. The reaction mixture was digested by $D p n$ I for $2 \mathrm{~h}$ to remove the template DNA and transformed into XL1Blue super competent cells (Stratagene) for selection of mutant clones. Mutations were confirmed by DNA sequencing.

Electrophoretic Mobility Shift Assay (EMSA). Double-stranded synthetic probes containing the HNF $4 \alpha$ binding site were labeled with $\left[{ }^{35} \mathrm{~S}\right]$ dATP by filling-in reaction using the Klenow fragment of DNA polymerase I. Nuclear receptor HNF4 $\alpha$ was synthesized in vitro using Quickcoupled Transcription/Translation Systems (Promega) programmed with receptor expression plasmids according to the manufacturer's instruction. EMSA assay was performed as described in detail previously ( $\mathrm{Li}$ and Chiang, 2004).

Immunoblotting analysis. HepG2 cells were cultured in $100 \mathrm{~mm}$ dishes to $80 \%$ confluence. Cells were transfected with pcDNA3-HA-SHP plasmid (5 or $10 \mu \mathrm{g})$ and incubated in serum free media for $40 \mathrm{~h}$. Cell lysates were analyzed by SDS-polyacrylamide gel electrophoresis. Antibody against HA-tag (Santa Cruz Biotechnology, CA) were used for western blotting and detected by ECL Western blotting detection kit (Amersham Biosciences, UK). 
Chromatin immunoprecipitation (ChIP) assay. HepG2 cells were grown in $100 \mathrm{~mm}$ culture dishes to $80 \%$ confluence. HA-PGC-1 $\alpha(10 \mu \mathrm{g})$ or HA-SHP plasmid was transfected into HepG 2 cells. Cells were treated with $10 \mu \mathrm{M}$ rifampicin or vehicle (DMSO) in serum free media for $40 \mathrm{~h}$. ChIP assays were performed using ChIP Assay kit (Upstate Biotec, NY) according to manufacturer's protocol and described previously ( $\mathrm{Li}$ and Chiang, 2004). Ten percent of the cell lysates before immunoprecipitation was saved and used as "input". The cross-linked DNAprotein complexes were precipitated by incubating the cell lysates with $10 \mu \mathrm{g}$ of antibodies or non-immuno IgG (Santa Cruz Biotec. Inc, Santa Cruz, CA) followed by protein A-agarose beads. The antibodies used were: goat anti-HNF4 $\alpha$ (C-19), Cat\#: sc-6556, lot\#: I1203; rabbit anti-HNF4 $\alpha$ (H171), Cat\#: sc-8987, lot\#: K0204; goat anti-PXR (A-20), Cat\#: sc-7737, lot\#: J0704; rabbit anti-SRC-1 (M341), Cat\#: sc-8995, lot\#: C3004; goat anti-PGC-1 $\alpha$ (P-19), Cat\#: sc-5815, lot\#: I141; goat Normal IgG, Cat\#: sc-2027, lot\#: E1204; rabbit Normal IgG, Cat\#: sc-2028, lot\#: F0304.The beads were washed and samples eluted with $250 \mu \mathrm{l}$ of ChIP elution buffer. DNA fragments containing either dXREM or pER6 were PCR amplified for 35 cycles and analyzed on a $2 \%$ agarose gel. The PCR primers used were: dXREM region (dDR3/ER6, -7939 to -7576), forward-GCAGGTCCCCTGGAAAGTCAC, reverse-

CACCTGGGGTCAACACAGGAC; proximal ER6 region (-277 to -62), forwardATGCCAATGGCTCCACTTGAG, and reverse-CTGGAGCTGCAGCCAGTAGCAG; $2^{\text {nd }}$ intron region $(+1460$ to +1849), forward-GTTACTAGCTTCCTTCATCAGTTG, and reverseCATTCCAGCCTGGGCAACAAG.

GST pull-down assay. GST fusion protein isolation and GST pull down assays were described previously (Li and Chiang, 2004). The ${ }^{35}$ S-labeled proteins were generated using their respective expression plasmid in the TNT rabbit reticulocyte system (Promega) in the presence of ${ }^{35}$ S-labeled methionine. GST-fusion proteins $(\sim 1 \mu \mathrm{g})$ bound to the glutathione beads were added to $5 \mu \mathrm{l}$ of the ${ }^{35} \mathrm{~S}$-labeled proteins. In competition assays, $50 \mu \mathrm{l}$ of un-labeled TNT lysates incubated with pcDNA3 or indicated expression plasmids was added to the mixture. The beads were washed and the proteins eluted for analysis on an SDS PAGE gel. One $\mu 1^{35}$ S-labeled protein was loaded as "Input".

Statistical analysis. Data were plotted as means \pm standard deviation. Statistical analyses of treated vs. untreated controls (vehicle or empty plasmids) were performed using Student's $t$ test. A $p<0.05$ is considered statistically significant.

\section{RESULTS}

Rifampicin induces CYP3A4 but inhibits SHP mRNA expression in primary human hepatocytes. We assayed the effect of rifampicin on CYP3A4, SHP and CYP7A1 mRNA expression in primary human hepatocytes (Figure 1). Rifampicin dose-dependently induced CYP3A4 mRNA expression by almost 150 -fold at $10 \mu \mathrm{M}$. Interestingly, rifampicin strongly reduced SHP mRNA levels at a concentration as low as $1 \mu \mathrm{M}$. This is in contrast to the induction of SHP expression by bile acids via activation of FXR. As a positive control, rifampicin strongly inhibited CYP7A1 mRNA expression as previously reported (Li and Chiang, 2004). These data suggest that rifampicin activates PXR to induce CYP3A4, but reduces SHP mRNA expression. HNF4 $\alpha$, SRC-1 and PGC-1 $\alpha$ co-activate, whereas SHP inhibits PXR induction of human CYP3A4 gene transcription. The marked induction of CYP3A4 by rifampicin prompted us to investigate the molecular mechanism of PXR induction of the human CYP3A4 gene. Nuclear receptor activity is enhanced by co-activators and inhibited by co-repressors. SRC-1 and PGC- $1 \alpha$ are known to enhance HNF4 $\alpha$ and PXR trans-activation activity (Li and Chiang, 2004). We reported previously that rifampicin-activated PXR inhibited CYP7A1 gene transcription by interacting with HNF4 $\alpha$ and blocking PGC-1 $\alpha$ recruitment to CYP7A1 chromatin (Li and Chiang, 2004). We performed reporter assays to study the effect of HNF $4 \alpha$, PGC- $1 \alpha$ and SRC-1 on PXR regulation of the human CYP3A4 gene. We used a 
CYP3A4 reporter that contains a well-characterized distal XREM (-7800/-7600, containing an HNF4 $\alpha$ and two PXR binding sites) linked to a $5^{\prime}$ flanking fragment (-262/+11, containing a PXR site). Fig. 2A shows that cotransfection of this CYP3A4-Luc reporter plasmid with PXR and RXR $\alpha$ expression plasmids in HepG2 cells stimulated the basal reporter activity by about 3 -fold. Rifampicin $(10 \mu \mathrm{M})$ further stimulated CYP3A4 reporter activity by 4 -fold.

Surprisingly, we found that HNF4 $\alpha$ did not have any effect on the CYP3A4 reporter activity. Co-transfection with both HNF4 $\alpha$ and PXR caused a 2.5-fold stimulation of the CYP3A4 reporter activity stimulated by PXR alone when rifampicin was added. Fig. 2B shows that SRC-1 and/or PGC-1 $\alpha$ stimulated PXR induction of CYP3A4 reporter activity by 2 -fold in the absence of rifampicin. Addition of rifampicin further stimulated reporter activity. The maximal induction (about 130-fold) of the CYP3A4 basal reporter activity by rifampicin was achieved when PXR, HNF4 $\alpha$, SRC-1 and PGC-1 $\alpha$ were transfected. It is noted that inclusion of $\mathrm{HNF} 4 \alpha$ in the assay greatly enhanced rifampicin induction of the reporter activity suggesting that PXR and HNF4 $\alpha$ synergy is important for induction of CYP3A4. These data suggest that to maximize rifampicin induction of CYP3A4 gene transcription requires $\mathrm{HNF} 4 \alpha$ and coactivators.

HNF4 $\alpha$ does not directly regulate CYP3A4 gene transcription. Our result that HNF4 $\alpha$ alone did not affect CYP3A4 reporter activity is in contrast to a previous report that HNF4 $\alpha$ stimulated CYP3A4-Luc reporter activity (Tirona et al., 2003). EMSA shown in Fig. 3A confirmed that the putative HNF4 $\alpha$ binding site in the dXREM of the CYP3A4 gene was able to bind HNF4 $\alpha$ as the oligonucleotide probes designed according to a canonical DR1 motif and the HNF4 $\alpha$ binding sites in the CYP8B1 and CYP7A1 genes. Excess of unlabeled DR1 probe was able to compete out HNF4 $\alpha$ binding to the radiolabeled 8B1, 7A1 and 3A4 probes. We then performed site-directed mutagenesis to mutate the putative HNF4 $\alpha$ binding site in the CYP3A4 reporter plasmid. The mutant 3A4 probe did not bind HNF4 $\alpha$ (data not shown). Fig. 3B shows that mutations of the HNF4 $\alpha$ site in the CYP3A4 reporter plasmid did not affect the basal reporter activity and the synergistic stimulation of reporter activity by PXR and HNF4 $\alpha$. These results suggested that HNF $4 \alpha$ could stimulate CYP3A4 reporter activity without binding to the CYP3A4 gene. To further demonstrate that HNF4 $\alpha$ could interact with PXR without binding to DNA, mammalian one-hybrid assay was performed. Fig. 3C demonstrated that HNF4 $\alpha$ could stimulate a Gal4 reporter (5XUAS-Luc) activity induced by binding of Gal4DBD-PXR fusion protein to the upstream activation sequence (UAS) of the Gal4 DNA binding domain. All these results support that HNF4 $\alpha$ interaction with PXR synergistically stimulates CYP3A4 gene transcription and the putative HNF4 $\alpha$ binding site in the CYP3A4 gene may not be important in promoter function.

SHP inhibits CYP3A4 reporter activity. A previous study shows that SHP inhibits CYP3A4 reporter activity and blocks PXR binding to DNA in EMSA assay (Ourlin et al., 2003). We studied the effect of SHP on CYP3A4 reporter activity stimulated by PXR and HNF4 $\alpha$ in HepG2 cells. Fig. 4A shows that SHP inhibited PXR stimulation of CYP3A4 reporter activity when activated in the presence of rifampicin. Fig. 4B shows that SHP also inhibited CYP3A4 reporter activity that was synergistically stimulated by PXR and HNF4 $\alpha$ in the presence of rifampicin. However, our EMSA assay failed to confirm that SHP prevents PXR binding to the PXR binding site in the CYP3A4 gene (data not shown). This discrepancy may be due to the amount of SHP used in the assay. We used in vitro translated SHP, which typically contains ng quantity of translated proteins whereas Ourlin et al. used $9 \mu \mathrm{g}$ GST-SHP fusion protein in EMSA assays.

\section{Mammalian two-hybrid assays of SHP inhibition of PXR interaction with co-}

activators. We then performed cell-based mammalian two-hybrid assays in HepG2 cells to study the effect of SHP on PXR interaction with HNF4 $\alpha$, SRC-1 and PGC-1 $\alpha$. Gal4-fusion proteins should bind to the Gal4 binding site in the reporter plasmid 5XUAS-TK-Luc. If a 
Gal4-fusion protein interacts with a VP16 activation domain-fusion protein, the reporter activity should be stimulated. Addition of a competitor protein may disrupt the interaction and reduce the reporter activity. This assay is very sensitive in detecting protein-protein interaction without interference by endogenous transcription factors. Fig. 5A shows that Gal4-PXR strongly interacts with VP16-HNF4 $\alpha$, and rifampicin was required for the interaction. Addition of SHP strongly inhibited PXR/HNF4 $\alpha$ interaction. Similarly, Gal4-SHP interacted with VP16PXR in the presence of rifampicin, and HNF4 $\alpha$ inhibited the interaction (Fig. 5B). Therefore, HNF4 $\alpha$ and SHP competed for interaction with PXR. We did two-hybrid assays of Gal4-PXR interaction with VP16-SRC-1 or VP16-PGC-1 $\alpha$ to test if SHP inhibited PXR interaction with SRC-1 and PGC-1 $\alpha$. Fig. 5C shows that Gal4-PXR interacted with VP16-SRC-1 but SHP only partially inhibited the interaction. On the other hand, Gal4-PGC-1 $\alpha$ interacted with VP16-PXR, but SHP did not affect their interaction (Fig. 5D). These results indicated that HNF4 $\alpha$ and SHP competed for binding to PXR. However, SHP was unable to block PXR/PGC-1 $\alpha$ interaction and only partially blocked PXR/SRC-1 interaction.

GST pull-down assays of PXR interaction with HNF4 $\alpha$, SRC-1, PGC-1 $\alpha$ and SHP. GST pull down assay is a cell-free assay for studying specific protein-protein interactions. GSTHNF4 $\alpha$ (full-length) fusion protein or GST-hPXR (LBD) fusion protein strongly interacted with PXR or HNF4 $\alpha$, respectively, only when rifampicin was added to activate PXR (Fig. 6A). PXR interacted with SRC-1 in the absence of rifampicin, and addition of rifampicin enhanced their interaction. PXR interaction with PGC-1 $\alpha$ does not require rifampicin. The degrees of ligand-dependency for these co-activators to interact with PXR are consistent with mammalian two-hybrid assays shown in Fig 5. We next performed GST pull-down assays to study the effect of rifampicin on SHP interaction with PXR and HNF4 $\alpha$. In vitro translated and ${ }^{35}$ S labeled-PXR or SHP was used to interact with GST-SHP or GST-HNF4 $\alpha$, respectively. As shown in Fig. 6B, rifampicin strongly enhanced PXR and SHP interaction. However, rifampicin did not affect SHP interaction with HNF4 $\alpha$ as expected. We then added in vitro translated unlabeled-SHP or PXR to study their effect on interaction of ${ }^{35} \mathrm{~S}$-labeled PXR or SHP with HNF4 $\alpha$, respectively. Results shown in lower panels of Fig. 6B demonstrated that the amount of PXR or SHP that bound to GST-HNF4 $\alpha$ was decreased. These results provided additional evidence that SHP, PXR and HNF4 $\alpha$ interacted and competed for binding to each other.

ChIP assays of PXR and co-activator recruitment to CYP3A4 chromatin.

We then performed ChIP assays using HepG2 cells to study the effect of rifampicin on PXR recruitment of HNF4 $\alpha$, SRC- 1 and PGC- $1 \alpha$ to the CYP3A4 chromatin that contains PXR binding sites. ChIP assay is considered as an in vivo assay of transcription factor interaction and co-activator recruitment in the native promoter context. Since the levels of PGC- $1 \alpha$ are low in HepG2 cells, PGC-1 $\alpha$ was overexpressed in HepG2 cells for ChIP assays. An anti-body against PXR, HNF4 $\alpha$, SRC-1 or PGC-1 $\alpha$ was used to immunoprecipitate the cross-linked DNA-protein complexes in HepG2 cells treated with rifampicin or vehicle (DMSO). PCR primers were designed to amplify the DNA fragments containing either the distal XREM or the proximal ER6 from these complexes. Fig. 7A shows PCR products generated by the primer pairs for dXREM (left panels), pER6 (middle panels) and a negative control of the intron 2 region (right panel). The non-immune IgG was used as a negative control of immunoprecipitation for ChIP assays (bottom of each panel). The results indicated that PXR was associated with both chromatin and rifampicin did not affect PXR binding. The levels of HNF $4 \alpha$ associated with both dXREM and dER6 chromatins were very low and similar despite the presence of a HNF4 $\alpha$ binding site in dXREM but not in pER6. Rifampicin strongly induced the recruitment of HNF4 $\alpha$ to both chromatins, most likely via interaction with PXR. Rifampicin also induced PXR or HNF4 $\alpha$ recruitment of SRC- 1 to both chromatins. This is consistent with the enhanced binding of HNF4 $\alpha$ and SRC-1 to the PXR in the presence of rifampicin shown 
in Fig. 6A. It is surprising that rifampicin reduced the recruitment of PGC-1 $\alpha$ to both chromatins. This is in contrast to the GST pull down assay results (Fig 6A) that rifampicin had no effect on PGC-1 $\alpha$ interaction with PXR, and the two-hybrid assay results (Fig. 5D) that rifampicin enhanced PXR interaction with PGC-1 $\alpha$.

We then studied the effect of SHP on PXR recruitment of co-activators to the CYP3A4 chromatin. In experiments shown in Fig. 7B, rifampicin treated HepG2 cells were transfected with PGC-1 $\alpha$ and SHP or pcDNA3 empty plasmid as indicated. DNA-protein complexes were immunoprecipitated with an antibody against PXR, HNF4 $\alpha$, SRC-1 or PGC- $1 \alpha$ for ChIP assay. Fig. 7B shows that SHP did not affect PXR binding to either chromatin. However, SHP reduced PXR recruitment of HNF4 $\alpha$ and SRC-1 to both chromatins, whereas SHP did not affect PXR recruitment of PGC-1 $\alpha$. These data are consistent with mammalian two-hybrid assays (Fig. 5) and GST pull-down assays (Fig. 6) that SHP blocks PXR interaction with HNF4 $\alpha$ or SRC-1 but does not affect PXR and PGC-1 $\alpha$ interaction.

PXR inhibits SHP gene transcription. Since rifampicin strongly reduced SHP mRNA expression, we hypothesized that PXR might inhibit SHP gene transcription. We and others reported previously that HNF4 $\alpha$ binds to the human SHP promoter and stimulates SHP gene expression (Jung and Kullak-Ublick, 2003; Jahan and Chiang, 2005). Fig. 8A shows that HNF4 $\alpha$ and PGC-1 $\alpha$ stimulated SHP reporter activity in HepG2 cells independent of rifampicin. However, PXR strongly inhibited the SHP reporter activity stimulated by HNF $4 \alpha$ and PGC- $1 \alpha$ only when rifampicin was added. As a positive control, PXR inhibited the CYP7A1 reporter activity stimulated by HNF $4 \alpha$ and PGC- $1 \alpha$ in the presence of rifampicin (Fig. 8B) (Li and Chiang, 2004). In complete contrast, rifampicin-activated PXR markedly stimulated CYP3A4 reporter activity when HNF4 $\alpha$ and PGC-1 $\alpha$ also were transfected (Fig. $8 \mathrm{C})$. These data support our previous finding that PXR inhibits the HNF4 $\alpha$ target gene CYP7A1 by blocking HNF4arecruitment of PGC-1 $\alpha$ to CYP7A1 promoter (Li and Chiang, 2004). It appears the same mechanism also regulates the human SHP promoter. In contrast, PXR stimulates the PXR target gene CYP3A4. Taken together, our data suggest that HNF4 $\alpha$ enhances PXR induction of CYP3A4 by protein-protein interaction.

\section{DISCUSSION}

The ability to be strongly induced by a large variety of structurally unrelated compounds allows CYP3A4 to efficiently respond to elevated toxic metabolites such as bile acids and drugs and protects the liver against cholestasis induced by these compounds. Extensive studies in recent years have provided convincing evidence that PXR is the key regulator of phase I drug metabolizing enzymes, phase II bile acid and bilirubin conjugation enzymes and phase III drug and metabolites transporters (Boyer, 2005). PXR is the most important nuclear receptor that induces CYP3A4 to hydroxylate bile acids and drugs. However, most studies on PXR regulation of CYP3A4 were performed in mouse models. In this study we used the primary human hepatocyte and HepG2 models to study the molecular mechanism of human PXR regulation of CYP3A4. Our real-time PCR assays revealed a remarkable 150-fold induction of CYP3A4 mRNA expression by rifampicin in human primary hepatocytes. In contrast, rifampicin treatment reduced SHP and CYP7A1 mRNA expression. These data prompted us to study the mechanism of PXR regulation of CYP3A4 and SHP gene transcription. Our study revealed that interaction of PXR with HNF4 $\alpha$ and its co-activators PGC- $1 \alpha$ and SRC-1 contributes to the strong induction of CYP3A4 by rifampicin and that concomitant inhibition of SHP gene expression by PXR minimizes the inhibitory effect of SHP and maximizes PXR induction of CYP3A4. Several studies suggest the involvement of HNF4 $\alpha$ in regulation of the CYP3A4, CYP2C8 and CYP2C9 genes by PXR (Kamiya et al., 2003; Tirona et al., 2003; Chen et al., 2005; Ferguson et al., 2005). This study suggests that HNF4 $\alpha$ may act as a coactivator of PXR to recruit PGC- $1 \alpha$ and SRC- 1 to the PXR target gene CYP3A4. PXR interacts 
strongly with HNF4 $\alpha$, SRC-1, PGC-1 $\alpha$, and SHP. SHP may compete with HNF4 $\alpha$ and SRC-1 for binding to PXR and repress CYP3A4 gene transcription (Fig. 9). Therefore, to maximize the induction of CYP3A4, PXR must inhibit SHP gene transcription.

This study also revealed a general mechanism for PXR inhibition of HNF4 $\alpha$-activated gene transcription. Previous studies suggest that PXR inhibited CYP7A1 by blocking HNF4 $\alpha$ recruitment of PGC-1 $\alpha$ (Bhalla et al., 2004; Li and Chiang, 2004). This study revealed the same mechanism for PXR inhibition of the human SHP gene. It is significant that rifampicinactivated PXR inhibits both CYP7A1 and SHP expression, whereas bile acid-activated FXR induces SHP to inhibit CYP7A1. FXR has been shown to modestly regulate the CYP3A4 gene (Gnerre et al., 2004). It is reported recently that chenodeoxycholic acid and cholic acid induce SHP and repress PXR-mediated induction of CYP3A4 in human primary hepatocytes and in mice (Ourlin et al., 2003). Chenodeoxycholic acid and cholic acid are FXR ligands. Bile acid activation of FXR, PXR, and maybe also the signaling pathways in their study complicated the interpretation of their results. It is unlikely that FXR activation of CYP3A4 is a significant mechanism for bile acid induction of CYP3A4 because CYP3A4 can be induced without FXR (Schuetz et al., 2001). It seems clear that PXR and FXR regulate bile acid metabolism by somewhat different mechanisms; the secondary bile acid, LCA activates PXR to inhibit bile acid synthesis, increase bile acid excretion and detoxify bile acids, while the primary bile acid, CDCA activates FXR to inhibit bile acid synthesis and stimulate biliary bile acid excretion.

The CYP3A4 expression is affected by factors such as genetic polymorphism, hormonal status, cholestatic liver diseases, and exposure to drugs and xenobiotics. The induction of CYP3A4 varies widely among individuals and may account for different drug metabolizing activities and drug-drug interactions. PXR agonists such as rifampicin, dexamethasone, glucocorticoids, and phenobarbital have been used for treating chronic liver diseases for several decades without knowing the mechanism of drug action until the discovery of PXR in 1998. A recent study of gallstone patients taking rifampicin or ursodeoxycholic acid (UDCA) confirmed that rifampicin and UDCA induce hepatobiliary transport and detoxification systems and provided molecular mechanisms for these anti-cholestatic drugs (Marschall et al., 2005). Our current study provides a molecular mechanism for rifampicin induction of CYP3A4 in detoxification of bile acids and drugs during cholestasis. Drugs targeted to PXR may have potential for developing therapeutic drugs for treating cholestatic liver diseases induced by drugs.

\section{REFERENCES}

Bachs L, Pares A, Elena M, Piera C, Rodes J. Comparison of rifampicin with phenobarbitone for treatment of pruritus in biliary cirrhosis. Lancet 1989;1:574-576. [PubMed: 2564110]

Bertilsson G, Heidrich J, Svensson K, Asman M, Jendeberg L, Sydow-Backman M, Ohlsson R, Postlind $\mathrm{H}$, Blomquist P, Berkenstam A. Identification of a human nuclear receptor defines a new signaling pathway for CYP3A induction. Proc Natl Acad Sci U S A 1998;95:12208-12213. [PubMed: 9770465]

Bhalla S, Ozalp C, Fang S, Xiang L, Kemper JK. Ligand-activated PXR interferes with HNF-4 signaling by targeting a common coactivator PGC-1 $\alpha$ : Functional implications in hepatic cholesterol and glucose metabolism. J Biol Chem. 2004

Boyer JL. Nuclear receptor ligands: rational and effective therapy for chronic cholestatic liver disease. Gastroenterology 2005;129:735-740. [PubMed: 16083726]

Chen Y, Kissling G, Negishi M, Goldstein JA. The Nuclear Receptors Constitutive Androstane Receptor and Pregnane X Receptor Cross-Talk with Hepatic Nuclear Factor $4 \alpha$ to Synergistically Activate the Human CYP2C9 Promoter. J Pharmacol Exp Ther 2005;314:1125-1133. [PubMed: 15919766]

De Fabiani E, Mitro N, Gilardi F, Caruso D, Galli G, Crestani M. Coordinated control of cholesterol catabolism to bile acids and of gluconeogenesis via a novel mechanism of transcription regulation linked to the fasted -to-fed cycle. J Biol Chem 2003;278:39124-39132. [PubMed: 12865425] 
Drocourt L, Ourlin JC, Pascussi JM, Maurel P, Vilarem MJ. Expression of CYP3A4, CYP2B6, and CYP2C9 is regulated by the vitamin D receptor pathway in primary human hepatocytes. $\mathrm{J}$ Biol Chem 2002;277:25125-25132. [PubMed: 11991950]

Ferguson SS, Chen Y, LeCluyse EL, Negishi M, Goldstein JA. Human CYP2C8 is transcriptionally regulated by the nuclear receptors constitutive androstane receptor, pregnane $\mathrm{X}$ receptor, glucocorticoid receptor, and hepatic nuclear factor 4alpha. Mol Pharmacol 2005;68:747-757. [PubMed: 15933212]

Gnerre C, Blattler S, Kaufmann MR, Looser R, Meyer UA. Regulation of CYP3A4 by the bile acid receptor FXR: evidence for functional binding sites in the CYP3A4 gene. Pharmacogenetics 2004;14:635-645. [PubMed: 15454728]

Goodwin B, Hodgson E, Liddle C. The orphan human pregnane X receptor mediates the transcriptional activation of CYP3A4 by rifampicin through a distal enhancer module. Mol Pharmacol 1999;56:1329-1339. [PubMed: 10570062]

Goodwin B, Jones SA, Price RR, Watson MA, McKee DD, Moore LB, Galardi C, Wilson JG, Lewis MC, Roth ME, Maloney PR, Willson TM, Kliewer SA. A regulatory cascade of the nuclear receptors FXR, SHP-1, and LRH-1 represses bile acid biosynthesis. Mol Cell 2000;6:517-526. [PubMed: 11030332]

Goodwin B, Redinbo MR, Kliewer SA. Regulation of cyp3a gene transcription by the pregnane x receptor. Annu Rev Pharmacol Toxicol 2002;42:1-23. [PubMed: 11807162]

Guengerich FP. Cytochrome P-450 3A4: regulation and role in drug metabolism. Annu Rev Pharmacol Toxicol 1999;39:1-17. [PubMed: 10331074]

Hayhurst GP, Lee YH, Lambert G, Ward JM, Gonzalez FJ. Hepatocyte nuclear factor $4 \alpha$ (nuclear receptor 2A1) is essential for maintenance of hepatic gene expression and lipid homeostasis. Mol Cell Biol 2001;21:1393-1403. [PubMed: 11158324]

Hofmann AF. Rifampicin and treatment of cholestatic pruritus. Gut 2002;51:756-757. [PubMed: 12377823]

Jahan A, Chiang JY. Cytokine regulation of human sterol 12 $\alpha$-hydroxylase (CYP8B1) gene. Am J Physiol Gastrointest Liver Physiol 2005;288:G685-695. [PubMed: 15550563]

Jung D, Kullak-Ublick GA. Hepatocyte nuclear factor 1 alpha: a key mediator of the effect of bile acids on gene expression. Hepatology 2003;37:622-631. [PubMed: 12601360]

Kamiya A, Inoue Y, Gonzalez FJ. Role of the hepatocyte nuclear factor $4 \alpha$ in control of the pregnane X receptor during fetal liver development. Hepatology 2003;37:1375-1384. [PubMed: 12774017]

Kliewer SA, Goodwin B, Willson TM. The nuclear pregnane X receptor: a key regulator of xenobiotic metabolism. Endocr Rev 2002;23:687-702. [PubMed: 12372848]

Kliewer SA, Moore JT, Wade L, Staudinger JL, Watson MA, Jones SA, McKee DD, Oliver BB, Willson TM, Zetterstrom RH, Perlmann T, Lehmann JM. An orphan nuclear receptor activated by pregnanes defines a novel steroid signaling pathway. Cell 1998;92:73-82. [PubMed: 9489701]

Lehmann JM, McKee DD, Watson MA, Willson TM, Moore JT, Kliewer SA. The human orphan nuclear receptor PXR is activated by compounds that regulate CYP3A4 gene expression and cause drug interactions. J Clin Invest 1998;102:1016-1023. [PubMed: 9727070]

Li T, Chiang JY. Mechanism of Rifampicin and Pregnane X Receptor (PXR) inhibition of Human Cholesterol 7 $\alpha$-Hydroxylase Gene (CYP7A1) Transcription. Am J Physiol Gastrointest Liver Physiol. 2004

Lu TT, Makishima M, Repa JJ, Schoonjans K, Kerr TA, Auwerx J, Mangelsdorf DJ. Molecular basis for feedback regulation of bile acid synthesis by nuclear receptors. Mol Cell 2000;6:507-515. [PubMed: 11030331]

Marschall HU, Wagner M, Zollner G, Fickert P, Diczfalusy U, Gumhold J, Silbert D, Fuchsbichler A, Benthin L, Grundstrom R, Gustafsson U, Sahlin S, Einarsson C, Trauner M. Complementary stimulation of hepatobiliary transport and detoxification systems by rifampicin and ursodeoxycholic Acid in humans. Gastroenterology 2005;129:476-485. [PubMed: 16083704]

Ourlin JC, Lasserre F, Pineau T, Fabre JM, Sa-Cunha A, Maurel P, Vilarem MJ, Pascussi JM. The small heterodimer partner interacts with the pregnane $\mathrm{X}$ receptor and represses its transcriptional activity. Mol Endocrinol 2003;17:1693-1703. [PubMed: 12805410] 
Puigserver P, Rhee J, Donovan J, Walkey CJ, Yoon JC, Oriente F, Kitamura Y, Altomonte J, Dong H, Accili D, Spiegelman BM. Insulin-regulated hepatic gluconeogenesis through FOXO1-PGC-1 $\alpha$ interaction. Nature 2003;423:550-555. [PubMed: 12754525]

Schuetz EG, Strom S, Yasuda K, Lecureur V, Assem M, Brimer C, Lamba J, Kim RB, Ramachandran V, Komoroski BJ, Venkataramanan R, Cai H, Sinal CJ, Gonzalez FJ, Schuetz JD. Disrupted bile acid homeostasis reveals an unexpected interaction among nuclear hormone receptors, transporters, and cytochrome P450. J Biol Chem 2001;276:39411-39418. [PubMed: 11509573]

Shin DJ, Campos JA, Gil G, Osborne TF. PGC-1 $\alpha$ activates CYP7A1 and bile acid biosynthesis. J Biol Chem 2003;278:50047-50052. [PubMed: 14522988]

Staudinger JL, Goodwin B, Jones SA, Hawkins-Brown D, MacKenzie KI, LaTour A, Liu Y, Klaassen CD, Brown KK, Reinhard J, Willson TM, Koller BH, Kliewer SA. The nuclear receptor PXR is a lithocholic acid sensor that protects against liver toxicity. Proc Natl Acad Sci U S A 2001;98:33693374. [PubMed: 11248085]

Stroup D, Chiang JY. HNF4 and COUP-TFII interact to modulate transcription of the cholesterol $7 \alpha-$ hydroxylase gene (CYP7A1). J Lipid Res 2000;41:1-11. [PubMed: 10627496]

Tirona RG, Lee W, Leake BF, Lan LB, Cline CB, Lamba V, Parviz F, Duncan SA, Inoue Y, Gonzalez FJ, Schuetz EG, Kim RB. The orphan nuclear receptor HNF4 $\alpha$ determines PXR- and CAR-mediated xenobiotic induction of CYP3A4. Nat Med 2003;9:220-224. [PubMed: 12514743]

Xie W, Radominska-Pandya A, Shi Y, Simon CM, Nelson MC, Ong ES, Waxman DJ, Evans RM. An essential role for nuclear receptors SXR/PXR in detoxification of cholestatic bile acids. Proc Natl Acad Sci U S A 2001;98:3375-3380. [PubMed: 11248086] 

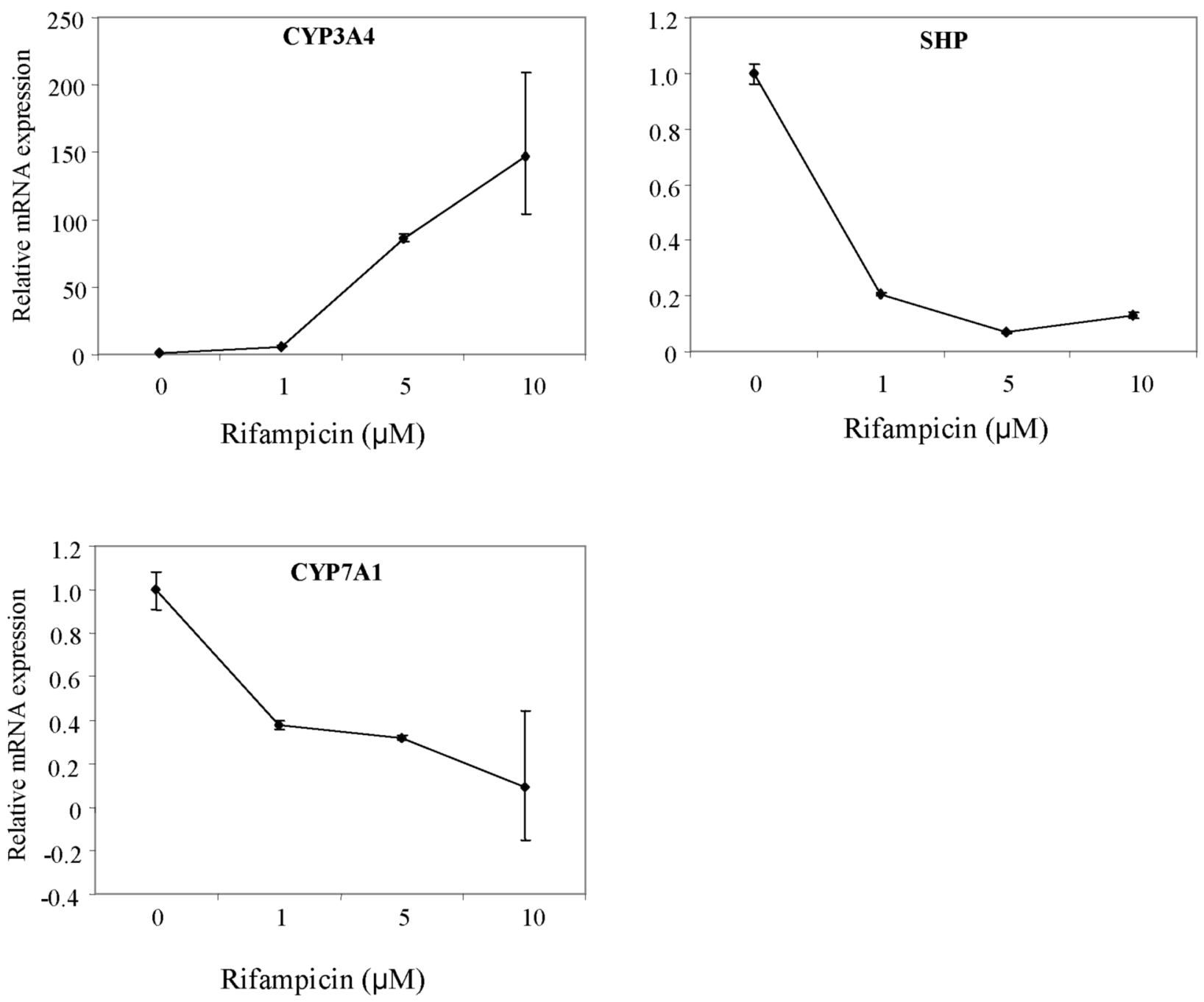

Fig. 1.

Real time PCR analysis of the effect of rifampicin on CYP3A4, SHP and CYP7A1 mRNA expression levels in primary human hepatocytes. Relative mRNA expression (un-treated control is set as 1) levels are plotted vs. concentrations of rifampicin. 
A.

CYP3A4-Luc

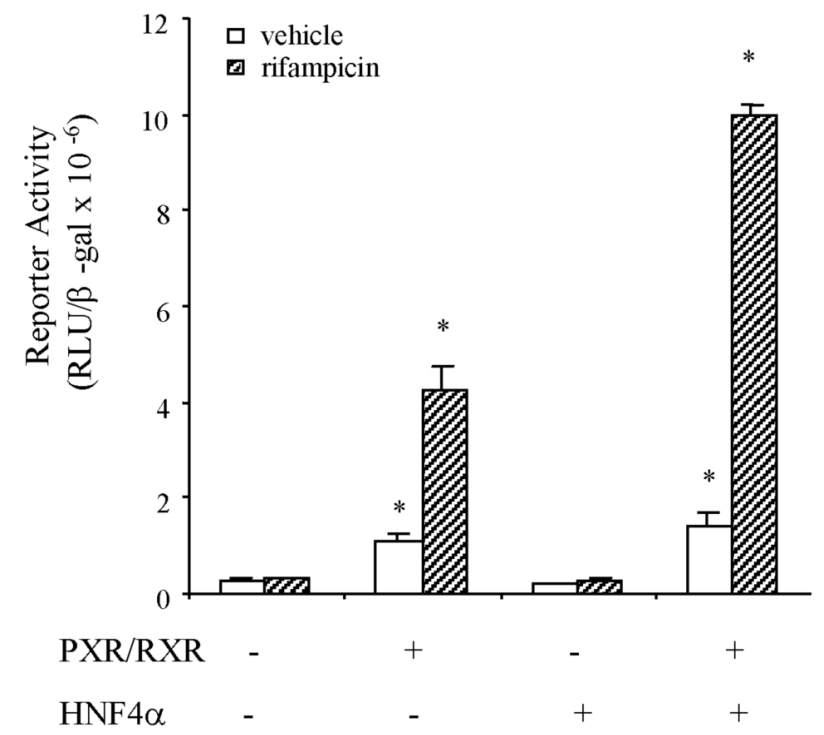

B.
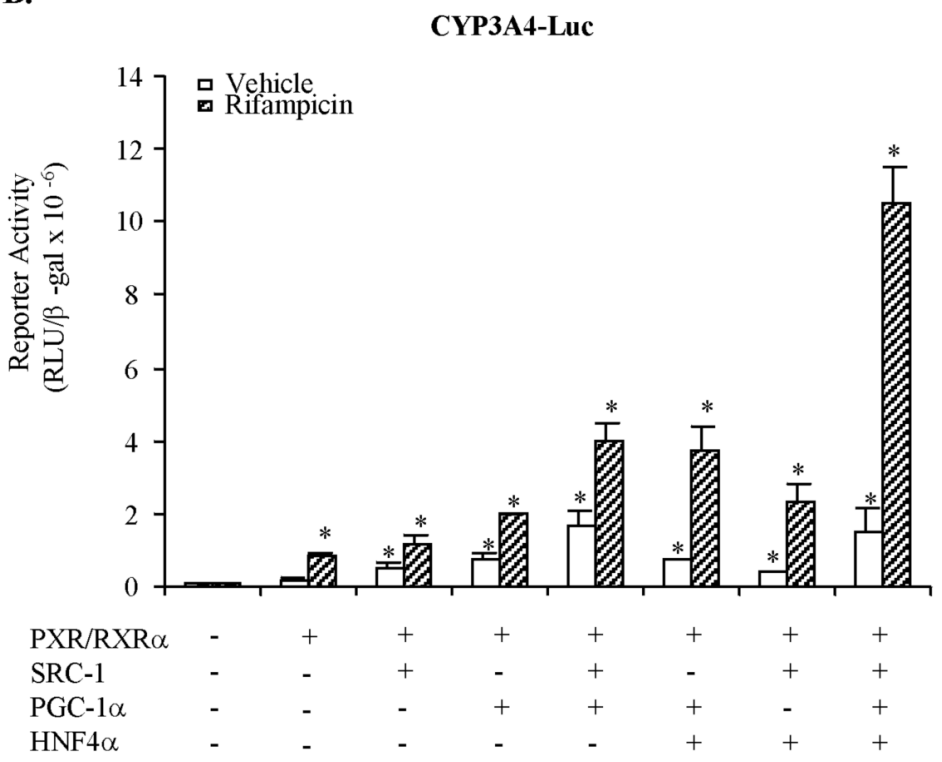

Fig. 2.

Effects of HNF $4 \alpha$ and co-activators on PXR regulation of the human CYP3A4 reporter gene. CYP3A4 luciferase reporter, p3A4-5'dDR3/dER6/pER6 (0.2 $\mu \mathrm{g})$ was co-transfected with PXR/RXR $\alpha$, SRC-1, HNF4 $\alpha$, and/or PGC- $1 \alpha(0.1 \mu \mathrm{g})$ into HepG2 cells as indicated in A \& B. Cells were treated with vehicle (DMSO) or $10 \mu \mathrm{M}$ rifampicin for $40 \mathrm{~h}$ and harvested for luciferase activity assays as described under Materials and Methods. The error bars represent the standard deviation from the mean of triplicate assays of an individual experiment, and “*”" indicates statistically significant difference from control, $N=3, p<0.05$. 
A.

\begin{tabular}{|l|ccccccc|}
\hline Probe & DR1 & $8 \mathrm{~B} 1$ & $7 \mathrm{~A} 1$ & $3 \mathrm{~A} 4$ & $8 \mathrm{~B} 1$ & $7 \mathrm{~A} 1$ & $3 \mathrm{~A} 4$ \\
\hline HNF4 $\alpha$ & + & + & + & + & + & + & + \\
\hline Cold DR1 & - & - & - & - & + & + & + \\
\hline
\end{tabular}

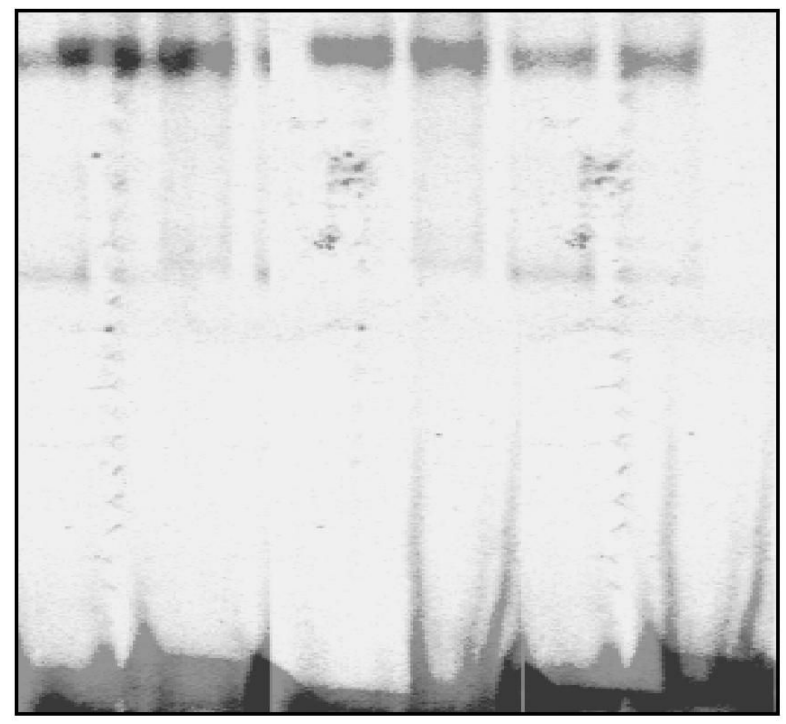

DR1: TTAGGTCAAAGGTCA

8B1: TTACAGGGCAAGGTCCAG

7A1: TTCTGTGGACTTAGTTCAAGGCCAGTT

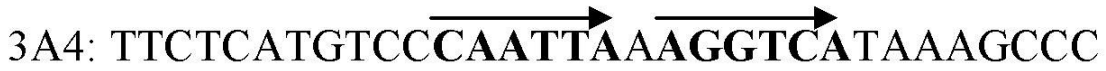

Fig. 3.

Synergistically induction of CYP3A4 by HNF4 $\alpha$ and PXR does not require HNF4 $\alpha$ binding to the CYP3A4 gene promoter. A. EMSA of HNF4 $\alpha$ binding to CYP3A4 dXREM. Probes containing a consensus HNF4 $\alpha$ binding site (DR1) or HNF4 $\alpha$ binding sites from CYP8B1 promoter (8B1), CYP7A1 promoter (7A1) and CYP3A4 dXREM (3A4) were labeled with $\mathrm{S}^{35} \mathrm{dATP}$. Each Probe $\left(5 \chi 10^{4} \mathrm{cpm}\right)$ and $5 \mu$ lof in vitro synthesized HNF4 $\alpha$ protein were mixed and applied to each lane as indicated. 100-fold excess of unlabeled DR1 probes were used as cold competitors. B. Luciferase reporter constructs $(0.2 \mu \mathrm{g})$ of wild type (WT) and mutant CYP3A4 (Mut) containing mutations in the dXREM HNF4 $\alpha$ binding site were transfected into HepG2 cells. Expression plasmids ( $0.1 \mu \mathrm{g})$ of PXR, RXR $\alpha$ and/or HNF4 $\alpha$ were co-transfected 
as indicated. Cells were treated with vehicle (DMSO) or $10 \mu \mathrm{M}$ rifampicin for $40 \mathrm{~h}$ and harvested for luciferase activity assays as described under Experimental Procedures. The error bars represent the standard deviation from the mean of triplicate assays of an individual experiment, and “*” indicates statistically significant difference from control, $\mathrm{N}=3, \mathrm{p}<0.05$. C. Mammalian one-hybrid assay of HNF4 $\alpha$ co-activation of PXR. HepG2 cells were transfected with 5XUAS-TK-Luc reporter $(0.2 \mu \mathrm{g})$ and $0.1 \mu \mathrm{g}$ expression plasmids: Gal4-PXR, PCDNA3 or HNF4 $\alpha$ as indicated. Cells were treated with vehicle (DMSO), or $10 \mu \mathrm{M}$ rifampicin for $40 \mathrm{~h}$. The error bars represent the standard deviation from the mean of triplicate assays of an individual experiment, and "*" indicates statistically significant difference from control, $\mathrm{N}=3, \mathrm{p}<0.05$. 
B.

CYP3A4-Luc

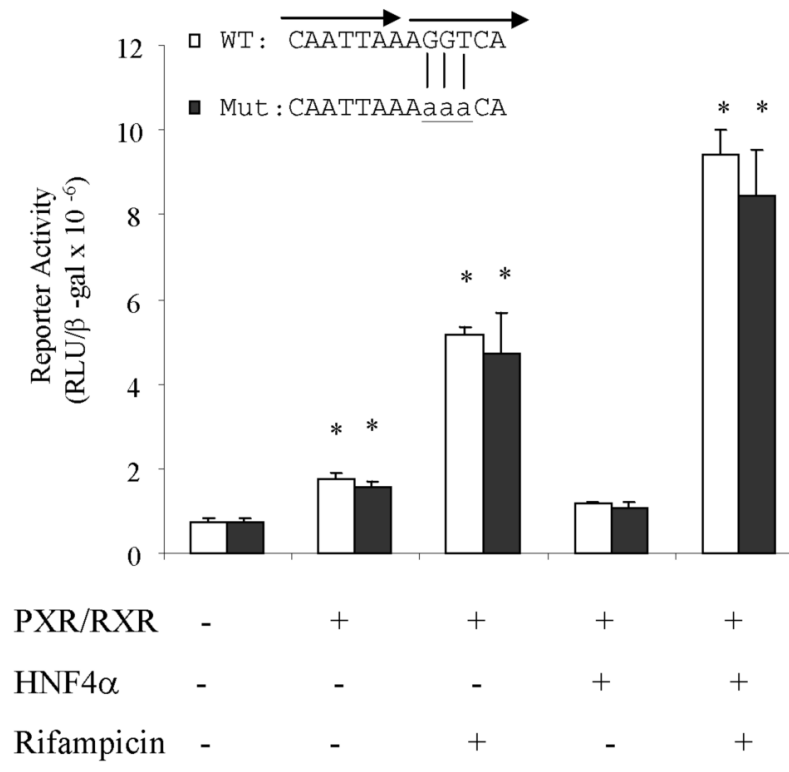

C.

5XUAS-TK-Luc

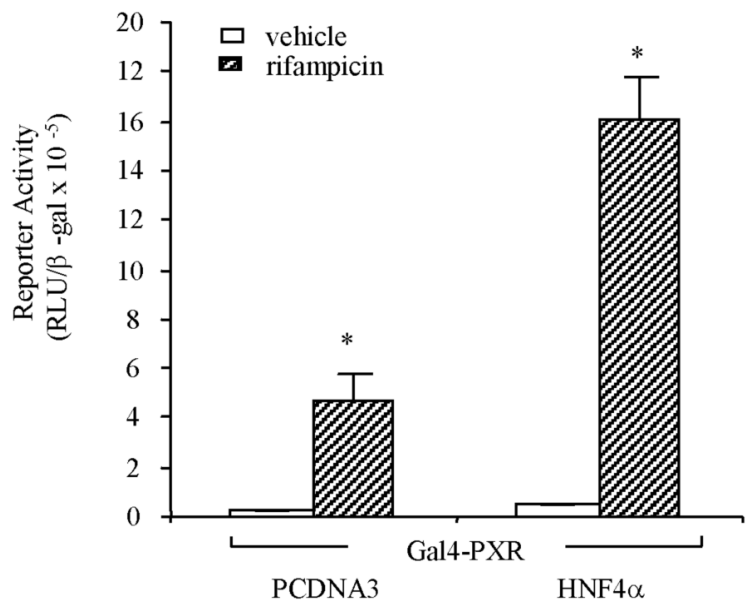


A.

CYP3A4-Luc

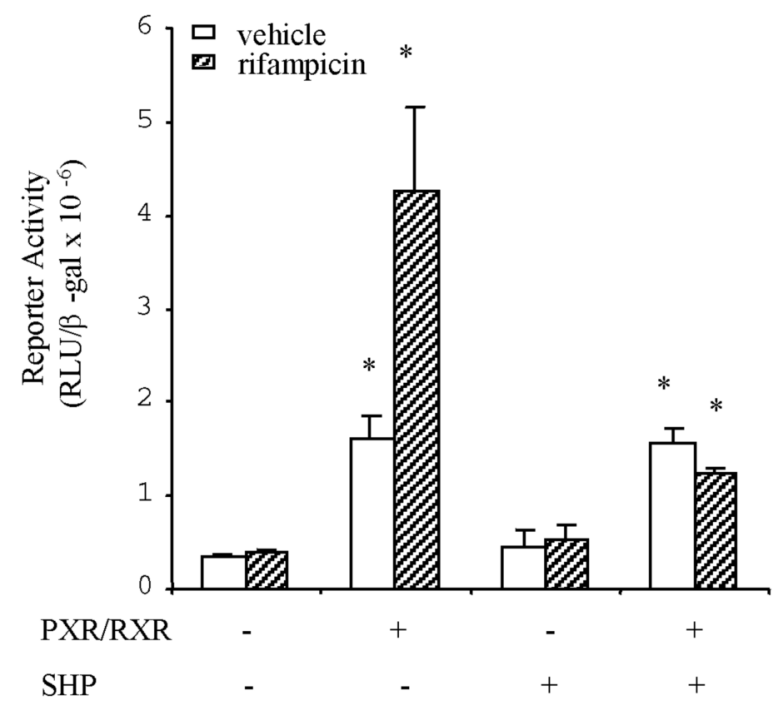

B.

CYP3A4-Luc

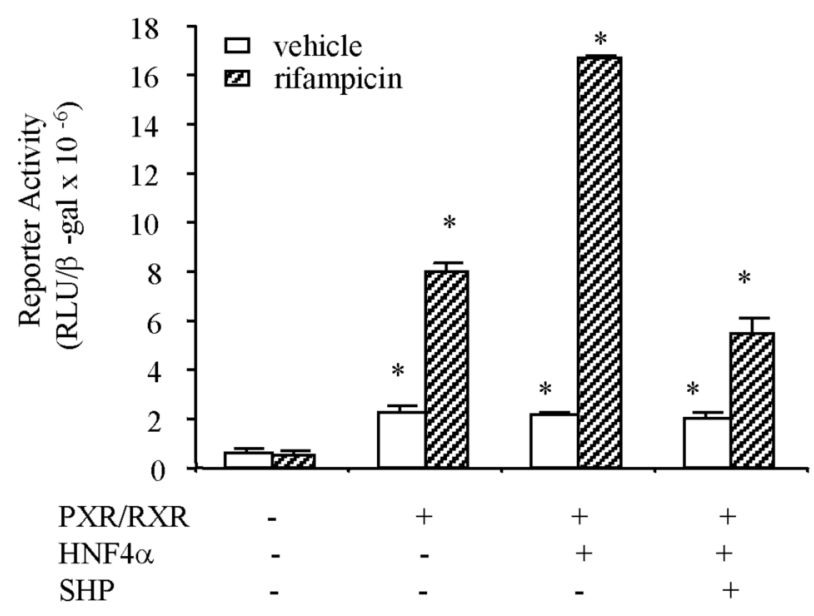

Fig. 4.

SHP inhibition of CYP3A4 reporter activity stimulated by PXR and HNF4 $\alpha$. Human CYP3A4 reporter, p3A4-5'dDR3/dER6/pER6 (0.2 $\mu \mathrm{g})$ was co-transfected with $0.1 \mu \mathrm{g}$ each of PXR/ $\mathrm{RXR} \alpha, \mathrm{HNF} 4 \alpha$ and SHP expression plasmids as indicated in (A) and (B). Reporter assays were performed and analyzed as in Fig. 2. 
A.

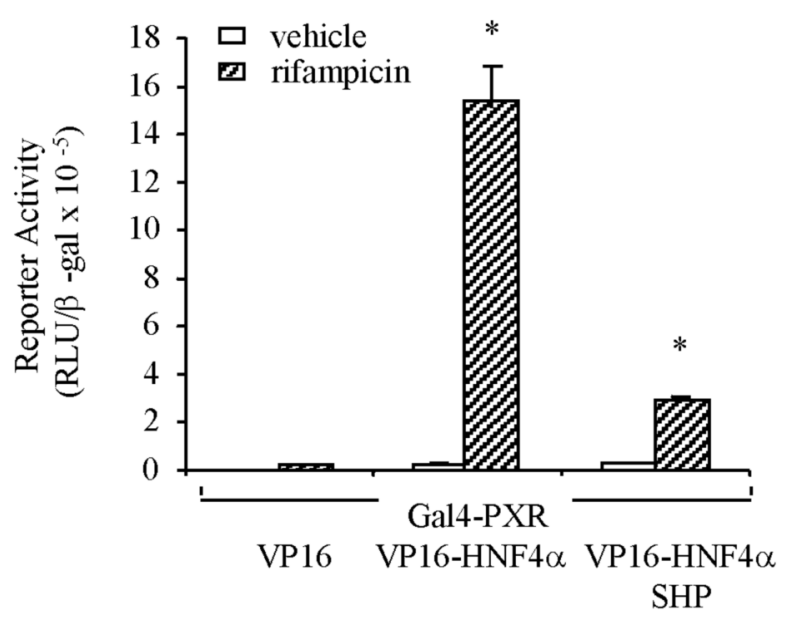

C.

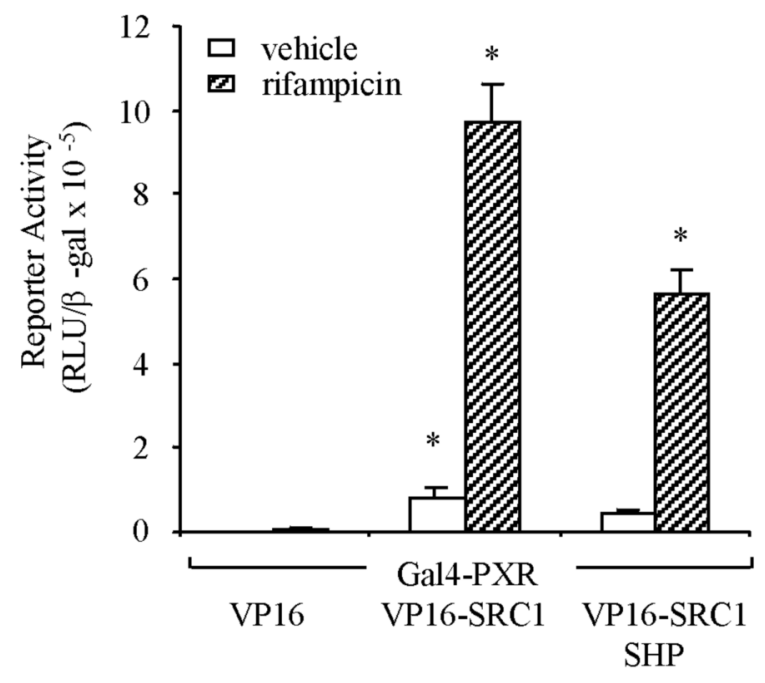

B.

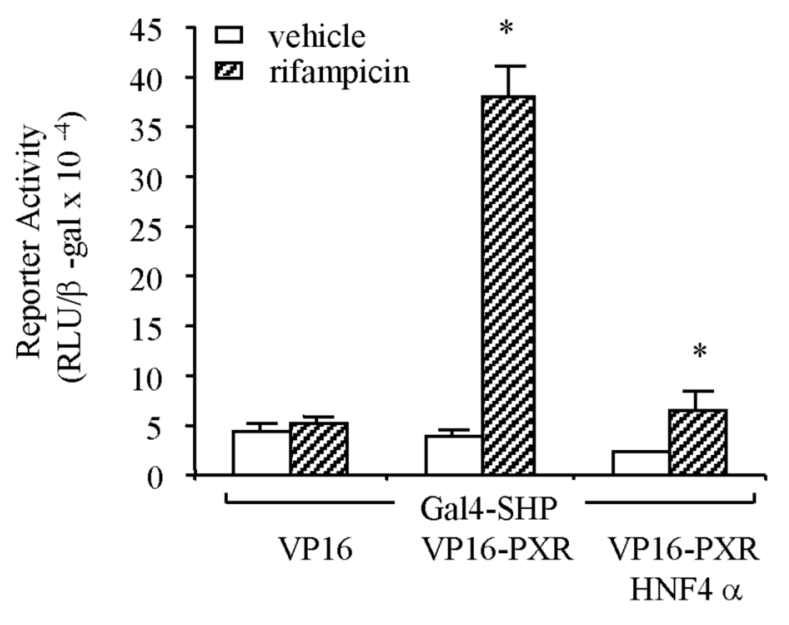

D.

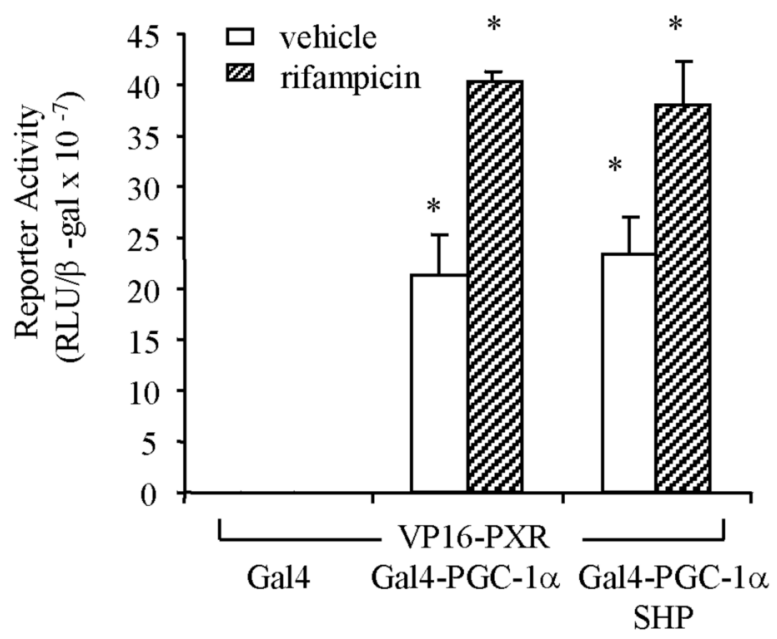

Fig. 5.

Mammalian two-hybrid assays of the effect of SHP on the PXR interaction with HNF4a, SRC-1 and PGC-1 $\alpha$. HepG2 cells were transfected with 5XUAS-TK-Luc reporter $(0.2 \mu \mathrm{g})$ and 0.1 $\mu \mathrm{g}$ expression plasmids: Gal4, Gal4-PXR, Gal4-SHP, Gal4-PGC-1 $\alpha$, VP16, VP16-HNF4 $\alpha$, VP16-PXR, VP16-SRC1, SHP and HNF4 $\alpha$, as indicated. Cells were treated with vehicle (DMSO), or $10 \mu \mathrm{M}$ rifampicin for $40 \mathrm{~h}$. The error bars represent the standard deviation from the mean of triplicate assays of an individual experiment, and “*” indicates statistically significant difference from control, $\mathrm{N}=3, \mathrm{p}<0.05$. 
A.
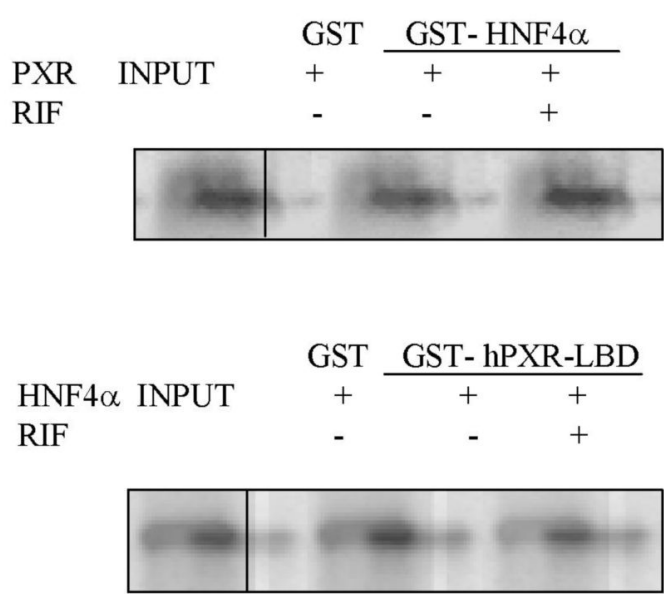

SRC-1 INPUT

GST GST- hPXR-LBD RIF
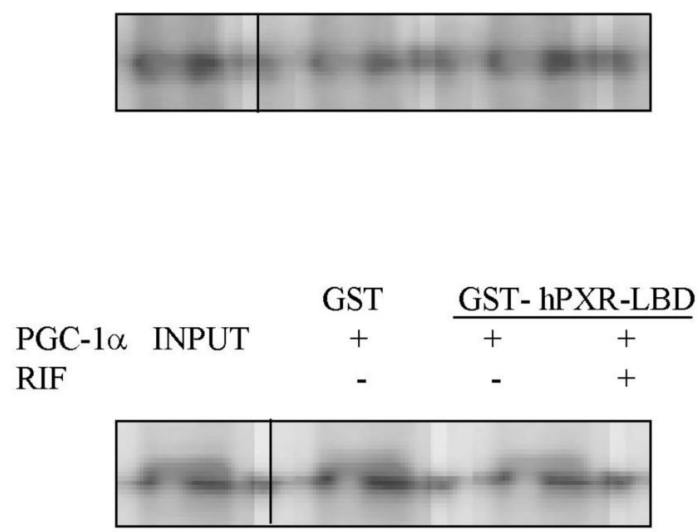

B.
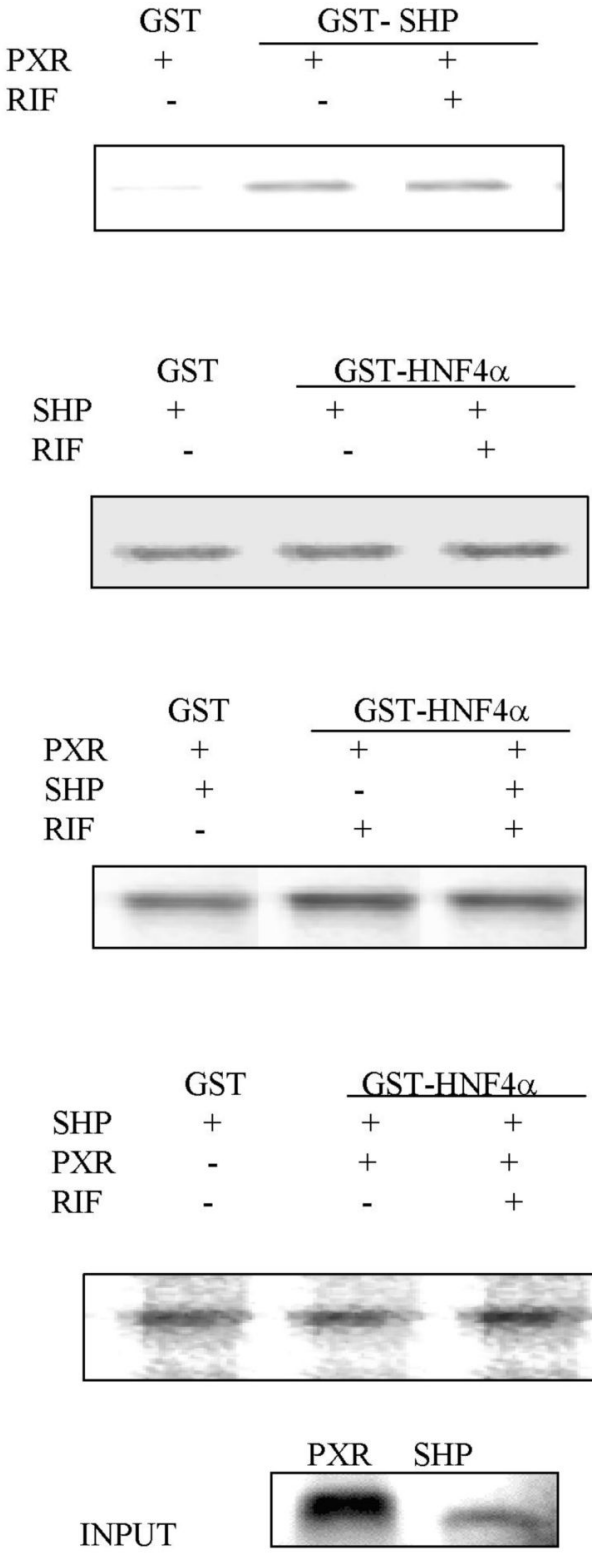

Fig. 6.

GST pull-down assays of PXR interactions with HNF4 $\alpha, S R C-1, P G C-1 \alpha$ and SHP. A. Effect of rifampicin on $\mathrm{HNF} 4 \alpha$, PXR, SRC-1 and PGC- $1 \alpha$ interaction. DMSO or $10 \mu \mathrm{M}$ rifampicin was added to the incubation mixture. B. Effect of SHP on HNF4 $\alpha$ and PXR interaction. GSTSHP fusion or GST-HNF4 $\alpha$ fusion was incubated with $5 \mu \mathrm{l}$ of ${ }^{35} \mathrm{~S}$-labeled, in vitro translated PXR or SHP, and/or un-labeled SHP or PXR as indicated. DMSO or $10 \mu \mathrm{M}$ rifampicin was added to the incubation mixture as indicated. One $\mu \mathrm{l}$ of the in vitro translated protein was used as "input". GST pull-down assays were performed as described under Experimental Procedures. 


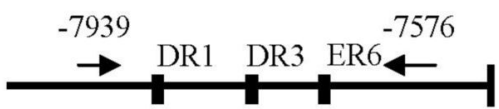

HNF4 $\alpha$ PXR PXR dXREM

A.

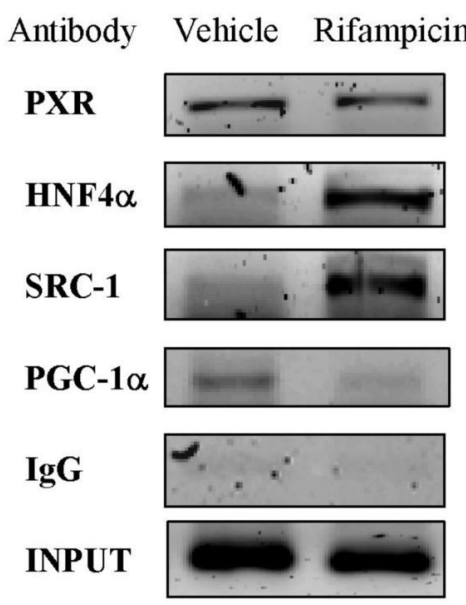

B.

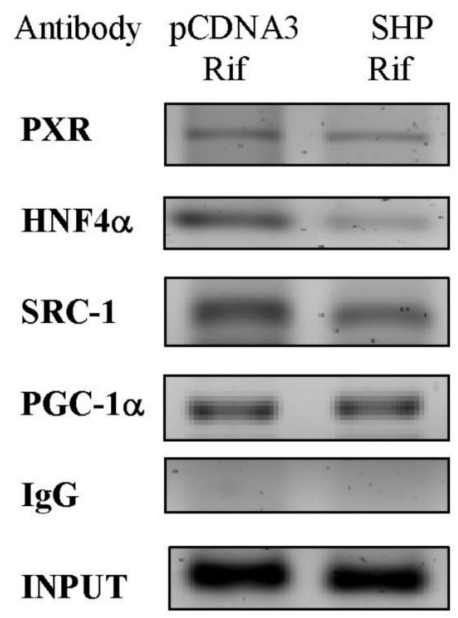

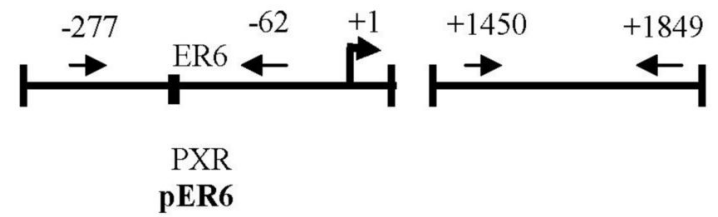

Vehicle Rifampicin

Vehicle Rifampicin
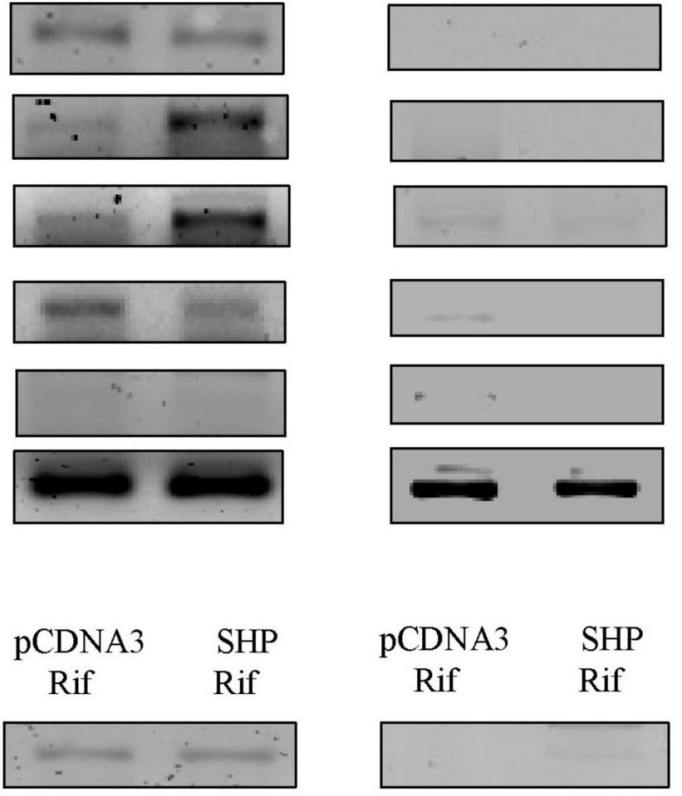

$\begin{array}{cl}\text { pCDNA3 } & \text { SHP } \\ \text { Rif } & \text { Rif }\end{array}$
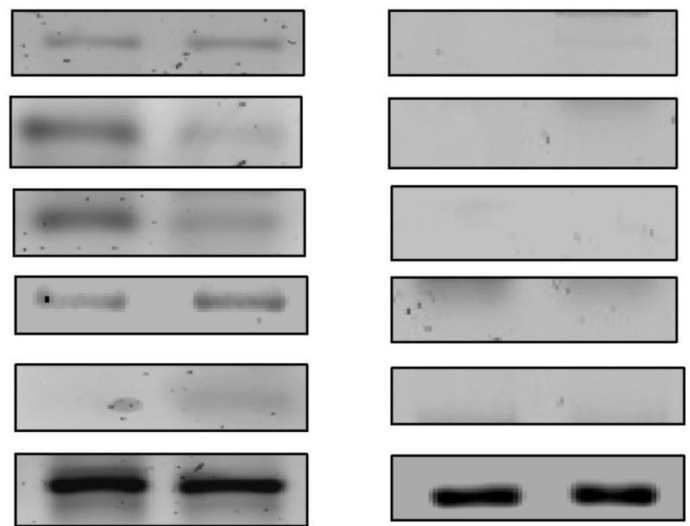

Fig. 7.

ChIP assay of the effect of rifampicin on PXR recruitment of $H N F 4 \alpha$, SRC-1, and PGC-1 to CYP3A4 chromatin. A (upper panels). HepG2 cells were transfected with $10 \mu \mathrm{g}$ PGC-1 $\alpha$ expression plasmids. Anti-PXR, anti-HNF4 $\alpha$, anti-PGC-1 $\alpha$, or anti-SRC- 1 antibodies was used to precipitate the DNA-protein complexes. B (lower panels). Effect of SHP on the PXR recruitment of HNF4 $\alpha$, SRC-1 and PGC-1 $\alpha$ to CYP3A4 chromatin. HepG2 cells were transfected with $10 \mu \mathrm{g}$ PGC- $1 \alpha$ and SHP expression plasmids or pcDNA3 empty plasmid as control for $40 \mathrm{~h}$. An antibody against PXR, HNF4, SRC-1 or PGC-1 was used to immunoprecipitate DNA-protein complexes. Cells were treated with $10 \mu \mathrm{M}$ rifampicin or vehicle (DMSO) as indicated for $40 \mathrm{~h}$. ChIP assays were performed as described under Material 
and Methods. DNA fragments containing distal XREM (left panel), proximal ER6 (middle panel) or $2^{\text {nd }}$ intron (right panel) was PCR amplified (illustrated on the top of figure) and analyzed on a $2 \%$ agarose gel. Normal IgG was used alone as non-immuno control. $10 \%$ of the total cell lysate was used as "input". 
A.

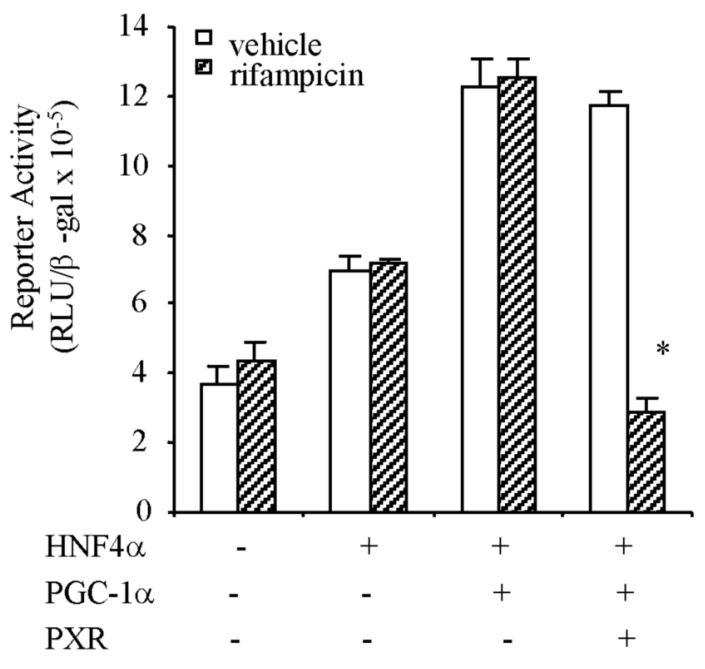

C.

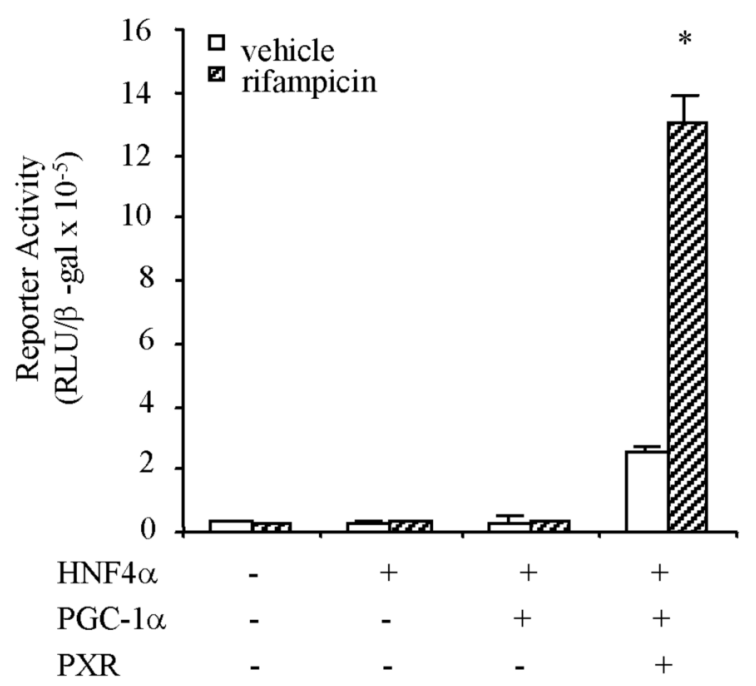

C.

\section{CYP3A4-Luc}

B.

CYP7A1-Luc

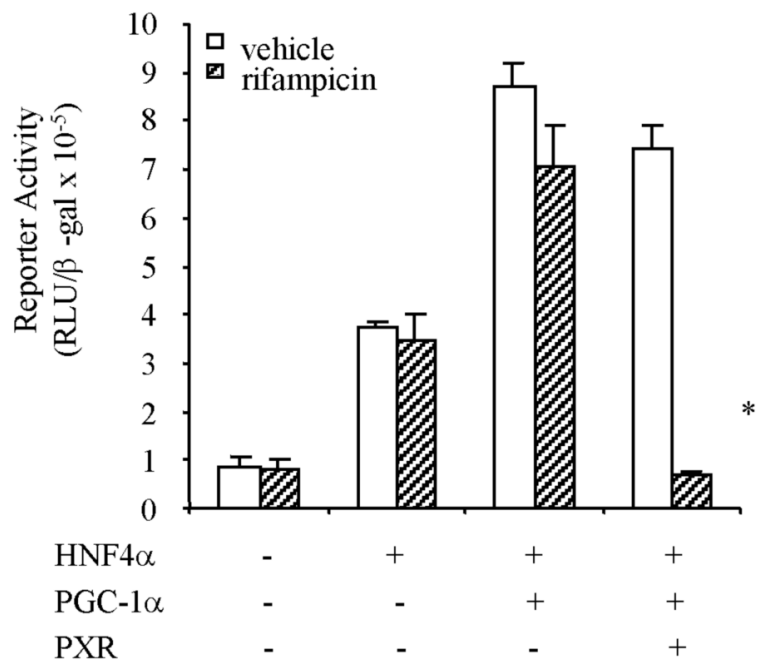

Fig. 8.

PXR regulation of SHP promoter activity. HepG2 cells were cultured to about $80 \%$ confluence. Human SHP-Luc (A), CYP7A1-Luc (B), or CYP3A4-Luc (C) reporter plasmid $(0.2 \mu \mathrm{g})$ was co-transfected with HNF4 $\alpha$, PGC- $1 \alpha$ or PXR expression plasmids $(0.1 \mu \mathrm{g})$ as indicated. Cells were treated with vehicle (DMSO), or $10 \mu \mathrm{M}$ rifampicin for $40 \mathrm{~h}$ and harvested for luciferase activity assays as described under Materials and Methods. The error bars represent the standard deviation from the mean of triplicate assays of an individual experiment, “*” indicates statistically significant difference from control, $N=3, p<0.05$. 


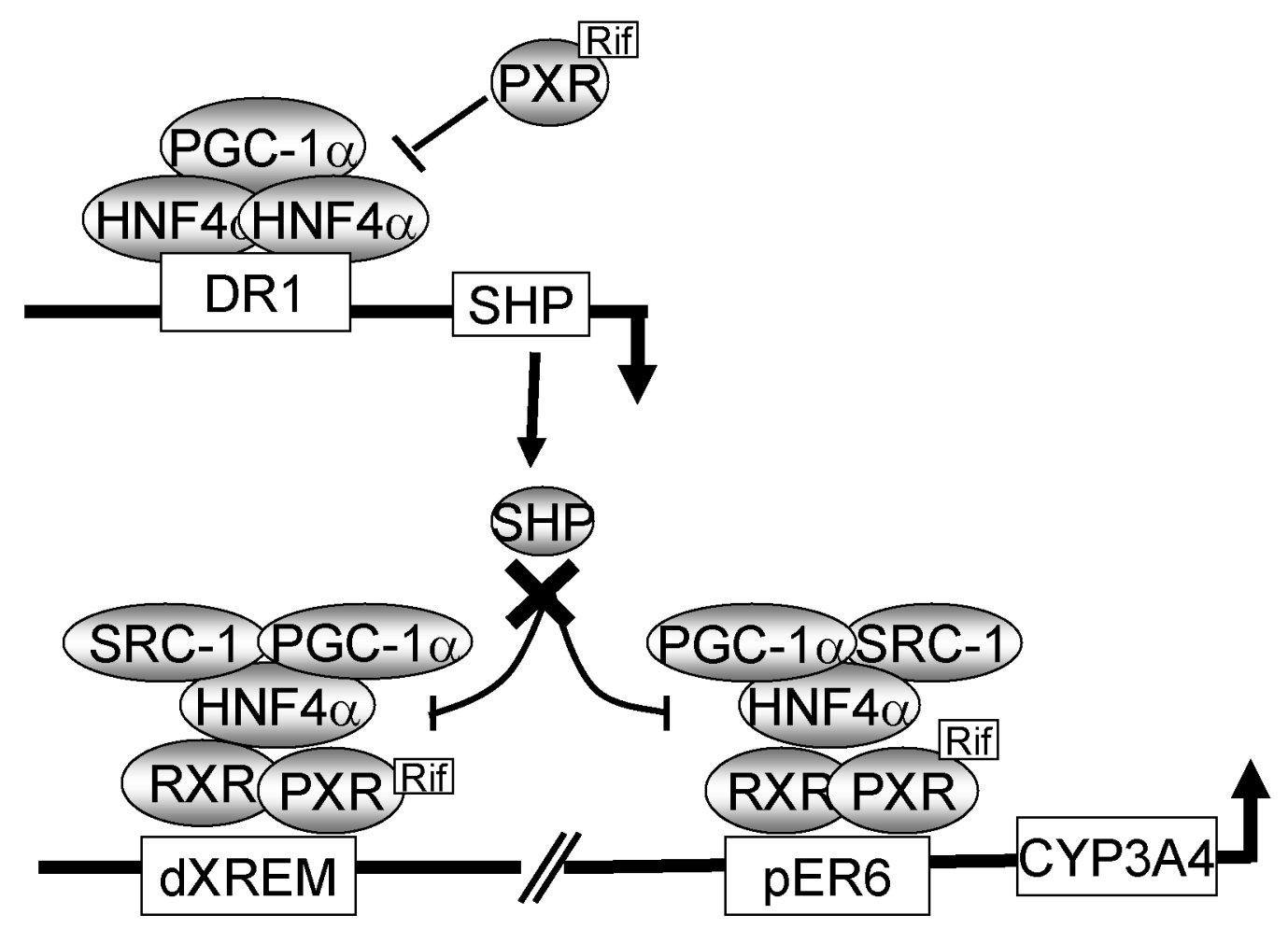

Fig. 9.

A model of PXR, HNF4 $\alpha$ and co-activator regulation of human CYP3A4 gene in hepatocytes. PXR/RXR $\alpha$ binds to $\mathrm{dXREM}$ and pER6 motifs in the human CYP3A4 promoter. Rifampicin induces PXR interaction with $\mathrm{HNF} 4 \alpha$, which is co-activated by PGC-1 $\alpha$ and SRC-1. HNF4 $\alpha$ binding site located upstream of dXREM may not be important in regulation of CYP3A4. SHP is able to inhibit CYP3A4 gene transcription by blocking PXR and HNF4 $\alpha$ interaction and recruitment of PGC-1 $\alpha$ and SRC- 1 to CYP3A4 chromatin. SHP gene transcription is induced by $\mathrm{HNF} 4 \alpha$, which binds to a DR1 motif in the SHP promoter. Rifampicin-activated PXR inhibits SHP transcription by blocking PGC-1 $\alpha$ recruitment to SHP chromatin. As a consequence, SHP expression is reduced and CYP3A4 transcription is maximized. 